\title{
READERS
nsight
}

Journal of Management Info (JMI)

ISSN:2313-3376

www.readersinsight.net/jmi

Mh

\section{Mediating effect of knowledge sharing between participative decision making, transformational leadership and organization performance}

\author{
Tahira Nazir ${ }^{1}$, Syed Fida Hussain Shah², Khalid Zaman ${ }^{3}$ \\ ${ }^{1}$ Department of Management Sciences, COMSATS Institute of Information Technology, Wah campus, Pakistan \\ ${ }^{2,3}$ Department of Management Sciences, COMSATS Institute of Information Technology, Abbottabad, Pakistan \\ *Corresponding author: fida@ciit.net.pk
}

\begin{abstract}
This is the era of information economy. Performance of the organization is credited to knowledge and information. Intellectual capital is considered to be the most important assets. But dilemma is that only some organization focus on generation and preservation of knowledge. Participative decision making and transformational leaders are great tools of successful implementation of Knowledge management practices. This study is intended to study the impact of the impact of Knowledge Sharing, Participative Decision Making and Transformational Leadership on Organization Performance. A survey instrument covering knowledge sharing (KS), participative decision making (PDM), transformational leadership (TL), and organizational performance was developed. Data was collected by postal and personal surveys from health, education, manufacturing, telecom, and financial sector of Gujranwala and Lahore region of Pakistan using stratified random sampling technique. Sample size was 300 and 245 complete questionnaires were received back with response rate of $81.7 \%$. The survey instrument used for the study was shown to be valid and reliable. Statistical analytical tools like (kindly mention all the tools) were used. Results of data analysis proposed a correlation between This study is probably the first to understand the impact of KM practices on organizational performance. It offers valuable information about KM to all the organizations particularly those operating in Pakistan.
\end{abstract}

\section{ARTICLE INFORMATION}

Received: 25 Jan 2014

Revised: 25 Feb 2014

Accepted: 25 March 2014

DOI:

http://dx.doi.org//10.31580/jmi.v1i1.2

Keywords: Knowledge Management, Knowledge Sharing, Transformational Leadership, Organizational Performance, Participative Decision Making

\section{Introduction}

Today the shift towards information economy enhances the importance of knowledge management. Information economy has completely changed the ways of doing business, because in this era performance is attributed to knowledge and information and it is as important as hardware development(Jarboe \& Alliance, 2011). Knowledge management practices are being admired for imparting techniques and tools to obtain, build, share and apply knowledge particularly tacit knowledge. Knowledge on the whole is combination of information and practice, background, explanation and manifestation(Jarboe \& Alliance, 2011). Business organizations are facilitated by Knowledge management (KM) because it assists in supervising knowledge personnel by coordinating, encouraging, praising and offering them cooperative working atmosphere (Gao, $\mathrm{Li}$, \& Clarke, 2008). Two individual factors have a great impact on knowledge-sharing process i.e. having confidence about knowledge and contentment in assisting people (Lin, 2007). An individual's information sharing approach is also influenced by group atmosphere and encouraging administration (Xue, Bradley, \& Liang, 2011). Employees' keenness towards collection and sharing of knowledge ensures the innovative potential of the organizations(Lin, 2007)., for this there is need of strong internal and external networks of communication, in this way you can congregate the customers' requirements in a superior manner. Transformational leadership style supports generating and disseminating knowledge at organizational level (both individual and group)(Bryant, 2003). This leadership style persuades the organizational goals and directs the high organizational performance. Such leaders consider employees as intellectual capital and focus on their personality, individual innovative capability and endorse effective communication linkages and confidence of gathering and spreading knowledge. If participative decision making is rooted in organizational culture it would grant better opportunity for knowledge sharing and problem solving through team discussions but it is entirely up to coaching behavior of empowering leaders(Arnold, Arad, Rhoades, \& Drasgow, 2000). Variety of task and work effort encourages the Participative decision making, which boosts the innovative aptitude of staff, amplifies job satisfaction and it has definitive effect on organizational performance (Liu, Chang, \& $\mathrm{Hu}, 2010$ ).

Now a days, knowledge is considered to be most essential asset in all types of organizations, still significant importance has not been given to knowledge management practices in developing countries like Pakistan. Unawareness of the managers about the long term benefits of knowledge management is major hurdle in developing knowledge sharing culture. Managers vacillate to delegate their authorities and reluctant to build participative decisions making environment because they think it weakens their management powers. There are number of multifaceted questions about maintaining such a widespread knowledge, hamper managers for executing knowledge management 
practices. Some of the questions are what kinds of people are required? What skills they need? What management style is essential? What type of organizational setups prop up knowledge sharing and the role of participative decision making in knowledge sharing(Bano, Rehman, \& Khan, 2010). Mangers in Pakistan consider that knowledge management is not their responsibility, it is problem of business and they don't pay much attention to it(Bano, Rehman, \& Khan, 2010).Managers are disinclined to encourage employees to take part in decision making and share knowledge because in this way they have threat to lose extent of control. Absence of motivation and lack of empowerment badly smashes self-confidence of the employees. This suppresses employees' creativity and innovative powers, thus depriving organization from novel ideas. In the eve of information economy managers must realize the importance of knowledge management moreover, its alignment with organizational strategy helps in achieving competitive advantage. Therefore this research was initiated to analyze the impact of Knowledge Sharing, Participative Decision Making and Transformational Leadership on Organization Performance.

\section{Literature review}

Knowledge-sharing process is considerably affected by two individual factors; one of them is feeling of pleasure in assisting people and the other is self-confidence on the knowledge. Executives' shore up which is one of the organizational factors also has great impact on knowledge sharing processes. It is also pointed out by results that Innovation capability of firm is facilitated by how much the employees are eager to collect and share knowledge (Lin, 2007).

Success of small Information Communications Technology firms depends upon information and knowledge. Key for the achievement of competitive advantage is knowledge and its implementation. Effective internal systems have been developed by the companies to flow the information and knowledge sharing. To gather the external knowledge, proficient methods are used and facts also showed that infantile national information system has also been developed to muster all possible knowledge. For such extensive information sharing networks definitely the credit goes to the owners of the firms because of their awareness about knowledge sharing and also to the development level(Harbi, Anderson, \& Amamou, 2011). Han and Anantatmula (2007) pointed out that knowledge sharing is significantly affected by leadership support, motivating structures in addition to it matters regarding accessibility and usability of technology also has great impact on knowledge sharing. Job insecurity is not any hurdle in the way of employee's eagerness to share knowledge.

According to Liu, Chang and $\mathrm{Hu}$ (2010) knowledge caliber depends upon the willingness of sharing knowledge and group distinctiveness. Work methods, task variety and social feedback are some of the attributes of task which significantly affect the group identity. Knowledge worker behaviors in the case of knowledge sharing cannot be ignored but it is quite difficult for managers to deal with them and these behaviors are affected by implied psychological contracts. Accurate evaluation about the nature of such psychological contract is very crucial so that managers can locate the key motivators through their knowledge sharing massages. Mostly psychological contract varies as the level of employment changes. Numbers of manuscripts have been presented to efficiently handle the all sort of psychological contracts and these are also helpful in minimizing PC breach perceptions(O’Neill \& Adya, 2007).

Lecturer performance is noticeably influenced by participative decision making and academic rank. The outcomes of the study indicated that performance of the lecturers get better through their participation in educational decision making processes and it also have great positive impact on the organizational performance as well. Moreover, academic rank is one of the important demographic factors which extensively affect lecturer performance(sukirno \& Siengthai, 2011). According to Parnell and Crandall (2001) propensities for participative decision making vary from manager to manager. To tackle this issue they create a new attuned parameter to assess the dedication and environmental constituents of the construct. Results of the study indicated that four factors are of great importance in manager's PPDM: having credence that participation is very valuable; having view that participation greatly affects the manager's power, organizational culture and last one is having the sense of true dedication to participative decision making. PDM is related to $\mathrm{X} / \mathrm{Y}$ assumptions according to McGregor's avowal, results of the study are in favor of this statement. Conclusions revealed that; according to theory $\mathrm{X}$ managers their power of decision making is negatively affected by PDM whereas according to $\mathrm{Y}$ theory managers allowing employees to take part in decision making, positively affect their administrative power and it eventually leads to organizational effectiveness.(Russ, 2011).

The findings of Selart (2005) pointed out that decision making through group participation mostly used by those managers who have squat peripheral powers, whilst managers having robust powers rarely use it. He also concluded that participative decision- making is more common in high externals rather than low externals. These results also proved that mangers mostly used participative decision making, as it is general tendency of managers. This research study indicated that Variety of task and work effort encourages the participation in decision making and this prop ups the job satisfaction and dedication with the organization (Ladd, Travaglione, \& Marshall, 2006)

While considering measurement differences Nigerian employees V/S US employees showed a different relation towards the emotional, conventional and persistence commitment in accordance with both actual Participative Decision Making and actual VS desired level of Participative Decision making .both level of participation actual and actual VS desired participation are linked with emotional and normative commitment of Nigerian employees . Continuance commitment is not linked with both of the measure of participation. Emotional and conventional organizational commitment of Americans were positively linked with only actual v/s desired level of PDM, however the continuance commitment was negatively linked with actual level of participation(Elele \& Fields, 2010).Carmeli, Shaeffer and Halevi (2009) found that those Top Management Teams which contains participatory decision making process shows a positive relation with decision effectiveness, although there is both direct and indirect relationship among the participatory decision making process and firm performance due to the decision effectiveness.

According to De Jong and Den Hartog (2007) 13 appropriate leadership behaviors are being present. Even though the innovative behavior is very important in such firms, but the researchers have not paid much attention towards it. Deliberate actions in addition to the everyday behavior of the leaders influence the employee innovative behavior whose purpose is to arouse the idea generation and its implementation.McGuire,Garavan,Saha\&O'Donnell (2006) gives the self-effacing assistance to the projected model which shows that the individual values influence the HR decision making, where the capability values and the peace values proves to be the important constructive forecaster of significance of wellbeing and protection and significance of employment justice respectively. Frucot\& White (2006) suggested that the self reported executive presentation and job fulfillment is being positively influenced by the both the managerial levels and budgetary participation.

There is a connection among personality and transformational leadership, but the ratings of subordinates and leaders are being diverged. The transformational leadership is being supported by the extraverted, intuitive and perceiving preferences in accordance to the leaders self rating whereas the subordinates rating signifies that the transformational leadership is being connected to the leaders sensing preference(Hautala, 2006). Parolini, Patterson and Winston (2009) found that transformational and servant leadership is being distinguished by the five statistically important distinguish objects. Revolutionary, evolutionary and transgressor are three types of transformational leaders which are being categorized by the environment-induced model of transformational leadership. Revolutionary transformational leaders probably come into sight in those organizations which are working in unstable environment and 
whose members demonstrate whether high or low level of interest yet on the other hand the evolutionary-transformational leaders probably appears in less unstable environment where members indicate the high level of interest and the transgressor leadership come out in less unstable environment but whose members reveals the less level of interest(Beugre, Acar, \& Braun, 2006).

In order to deal with the fast change the librarians are experimenting with organizational learning and new management styles. Library manager can study and implement the Transformational management styles. The proper survey has not been performed due to which the librarians' manger which was using the transformational management techniques to deal with the change remained ambiguous (Castiglione, 2006). Schneider and George (2011) suggested that there was a highly correlated relation between the transformational and Servant leadership methods. Servant leadership was recognized as an improved estimator of the voluntary club members' promise, fulfillment, and purpose to remain. The connection between servant leadership and fulfillment, promise, and purpose to remain in the volunteer service organizations steeled the Club members' perceptions of empowerment.

Gill, Flaschner and Sachnar (2006) suggested that leadership style of the management is linked with the degree of perceived stress which is further associated with the degree of perceived burnout. Leaders are more helpful to their employees as compared to developing the skills of their employees. Female leaders are more sacrificing than male leaders (Arnold \& Loughlin, 2010). Crossman (2010) points out that although there is harmony between spiritual administration and other value dependent approaches. But there is a need of developing model that develops insight of devout leadership in accordance with other assumptions.

Singh and Krishnan (2008) revealed that altruism and self-sacrifice can be categorized analytically. The link between transformational leadership and self-sacrifice is intervened by altruism. Perceived unit performance and followers' collective identity has direct relationship with transformational leadership. Cheung and Wong (2011) suggested that direct propinquity between transformational leadership and employees' imaginativeness grows more when there is strong affiliation and elevated ratio of chief's tasks.

Transformational commanders have the aptitude to influence their subordinates and their ideas about good man power and its benefits to the organization. They have great opportunities to enhance these benefits by engaging their employees in knowledge management, and developing such an environment where knowledge sharing between staff members is supported.(Birasnav, Rangnekar, \& Dalpati, 2011). According to Anantatmula (2010) there are different definitions of knowledge and importance in different organizations. Such system of knowledge management should be built up where every organization from the globe and its member irrespective of the origin can share their knowledge. Nguyen and Mohamed (2011) suggest that transactional and transformational leaders are part of knowledge management training. The study proposes that enigmatic bosses and extempore awards influence all aspects of knowledge management practices.

Watanabe and Senoo (2010) suggest that Knowledge management is influenced by administrative practices of a firm and the social environment of a country. But this research suggests that organizational idiosyncrasy appears to be more affecting determinant than a country's set of customs. An individual's information sharing attitude is impacted by group environment and encouraging administration. These two factors also impact overall knowledge communication stance within an organization (Xue, Bradley, \& Liang, 2011).

H1: There is significant association between knowledge sharing and organizational performance.

H2: There is significant association between participative decision making and organizational performance.

H3: There is significant association between transformational leadership and organizational performance.

\section{Methodology}

This research aims to examine the impact of knowledge sharing, participative decision making and transformational leadership on organization performance. To gather the most relevant data from the target population, a questionnaire survey was constructed based on two sections: Demographic and Subjective. Demographic section consists of Gender, Age, Marital Status, Sector, Industrial Composition, Establishment size and Job tenure. Subjective section consists of Knowledge Sharing, Participative decision making, Transformational Leadership and organizational performance. 39 Items are used to measure most significant aspects, which are critical in scrutinizing the impact of knowledge sharing, participative decision making and transformational leadership on organization performance. Whereas the measurement scale is 5-point Likert scale. 300 questionnaires were distributed among managers and employees and 245 out of 300 were received at the response rate of $81.7 \%$. Data is collected from financial institutions, health, education, and manufacturing and telecommunication sector of Lahore and Gujranwala region of Pakistan. The sample size of the study was 300 which was selected through stratified random sampling technique. 70 questionnaires were distributed in manufacturing organizations, and 70 questionnaires were distributed among Telecommunication sector and 60 questionnaires were distributed in financial sector and 50 questionnaire were distributed in each Health and Education sector. Administrative staff of the organizations was the sampling unit of this study. In order to collect data close ended questions were used to measure the impact of knowledge sharing, participative decision making and transformational leadership on organization performance. There were $79.6 \%$ male and $20.4 \%$ female.

\section{Results}

To scrutinize the impact of knowledge sharing, participative decision making and transformational leadership on organization performance descriptive statistics and Pearson moment correlation is applied, whilst Cronbach's alpha is also computed to measure the reliability of the analysis Pearson correlation coefficient was used to compute and analyze the association between each variable and through Descriptive statistics Mean and standard deviation were calculated to observe the tendency of respondents about each phenomenon. In Table 1 Correlation, mean, max and min values and standard deviation and Cronbach's alpha of each variable is given. Mean value of knowledge sharing was 3.57 that is close to 4 which means 245 respondents on average were agree about successful knowledge sharing processes and there is $75 \%$ total variation among their responses and Cronbach's alpha was 0.82 that shows $82 \%$ reliability of the survey about knowledge sharing of the respondents. Table 1 also shows that knowledge sharing is strongly correlated with organization performance. Mean value of 245 respondents about Participative decision making was 4.08 that shows positive tendency of respondents. 4.08 is close to 4 it means 245 respondents on average were agree about effective participative decision making approach and it plays significant role in improving organizational performance. There were $81 \%$ total variation among responses and Cronbach's alpha was 0.85 that shows $85 \%$ reliability of the survey about participative decision making of the respondents, Table 1 also shows that participative decision making is strongly correlated with organization performance.

Mean value of transformational leadership was 3.26 that is close to 3 which means 245 respondents on average were indifferent about leadership style and there is $92 \%$ total variation among their responses and Cronbach`s alpha was 0.84 that shows $84 \%$ reliability of the survey about transformational leadership of the respondents. Table 1 also shows that transformational leadership is strongly correlated with organization performance.

To test the relationship of knowledge sharing, participative decision making, transformational leadership and organization performance linear regression was computed however to test the normality of data and nature of correlation Durbin-Watson was also applied. 
Table 1: Pearson Moment Correlation, Mean, Standard Deviation and Cronbach`s Alpha $(N=245)$

\begin{tabular}{|c|c|c|c|c|c|c|c|c|c|}
\hline Description of Variables & Mean & Max & Min & SD & Alpha & 1 & 2 & 3 & 4 \\
\hline Knowledge Sharing & 3.57 & 5.00 & 1.80 & 0.75 & 0.82 & 1 & & & \\
\hline Participative Decision Making & 4.08 & 5.00 & 1.40 & 0.81 & 0.85 & $.599^{* *}$ & 1 & & \\
\hline Transformational Leadership & 3.26 & 4.80 & 1.40 & 0.92 & 0.84 & $.576^{\star *}$ & $.559^{* *}$ & 1 & \\
\hline Organizational Performance & 3.41 & 4.90 & 1.50 & 0.77 & 0.82 & $.633^{* *}$ & $.600^{* *}$ & $.525^{* *}$ & 1 \\
\hline
\end{tabular}

${ }^{* *}$. Correlation is significant at the 0.01 level (2-tailed).

Table 2: Model Summary

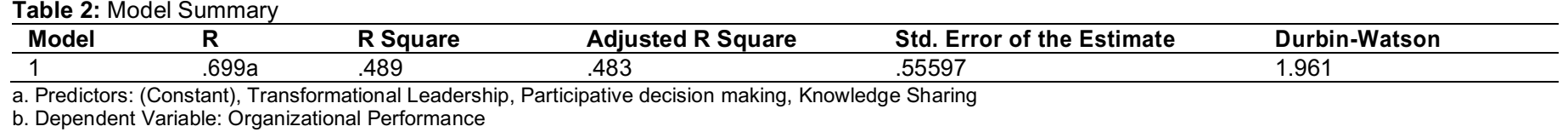

b. Dependent Variable: Organizational Performance

Table 3: ANOVA

\begin{tabular}{lllll} 
Table 3: ANOVA & & & & \\
\hline Model & Sum of Squares & df & Mean Square & F \\
\hline 1 & Regression & 71.331 & 3 & 23.777 \\
& Residual & 74.494 & 241 & .309 \\
& Total & 145.826 & 244 & \\
\hline
\end{tabular}

a. Predictors: (Constant), Transformational Leadership, Participative decision making, Knowledge Sharing

b. Dependent Variable: Organizational Performance

Table 4: Coefficients

\begin{tabular}{|c|c|c|c|c|c|c|c|c|}
\hline \multicolumn{3}{|c|}{ Model } & $\begin{array}{l}\text { Unstandardized Coefficients } \\
\text { Std. Error }\end{array}$ & $\begin{array}{l}\text { Standardized } \\
\text { Coefficients } \\
\text { Beta }\end{array}$ & $\mathbf{t}$ & Sig. & \multicolumn{2}{|c|}{$\begin{array}{l}\text { Collinearity Statistics } \\
\text { Tolerance VIF }\end{array}$} \\
\hline \multirow[t]{4}{*}{$\overline{1}$} & (Constant) & .495 & .199 & & 2.489 & .013 & & \\
\hline & Knowledge Sharing & .381 & .063 & .373 & 6.040 & .000 & .557 & 1.795 \\
\hline & Participative Decision making & .283 & .058 & .295 & 4.857 & .000 & .573 & 1.745 \\
\hline & Transformational Leadership & .122 & .050 & .145 & 2.437 & .016 & .597 & 1.675 \\
\hline
\end{tabular}

a. Dependent Variable: Organizational Performance

Table 2 shows $\mathrm{R}=0.669$ shows $66.9 \%$ variation in of knowledge sharing, participative decision making, transformational leadership and organization performance. $\mathrm{R}$ square is the coefficient of determination which shows $48.9 \%$ total variation in organizational performance due to predictors. Durban Watson test is applied to test the nature of autocorrelation; the value of $d$ is less than 2 so there is positive autocorrelation.

Table 3 of ANOVA shows level of significance since the value of $\mathrm{P}$ is less than significance level which is 0.05 so it is accepted that knowledge sharing processes, participative decision making and transformational leadership has signification association with organization performance.

In Table $4 \mathrm{~A}=.495$ is the average of organizational performance when knowledge sharing, is zero whereas .348 is the value of beta that shows one unit increase in knowledge sharing will bring .384 change in organization performance. Organizational Performance = $.495+.348$ (Knowledge Sharing). Above linear equation shows that one percent change in knowledge sharing will bring $34.8 \%$ change in organizational performance.

In Table $4 \mathrm{~A}=.495$ is the average of organizational performance when participative decision making is zero whereas .283 is the value of beta that shows one unit increase in participative decision making will bring .283 change in organization performance. Organizational Performance $=.495+.283$ (Participative Decision Making)

Above linear equation shows that one percent change in participative decision making will bring $28.3 \%$ change in organizational performance.

In Table $4 \mathrm{~A}=.495$ is the average of organizational performance when transformational leadership, is zero whereas .112 is the value of beta that shows one unit increase in transformational leadership will bring .112 change in organization performance. Organizational Performance $=.495+.112$ (Transformational Leadership)

Above linear equation shows that one percent change in knowledge sharing will bring $11.2 \%$ change in organizational performance.

According to Table 4 if tolerance value exceeds 5 and VIF exceeds 10 it means collinearity exists in data. Since here tolerance value and VIF values are less than 5 and 10 respectively so it shows there is no collinearity exists.

\section{Implications of the research}

The results of this study suggested that to be Knowledge based organization; an organization should incorporate knowledge sharing, participative decision making and transformational leadership. Knowledge sharing involves gathering and disseminating internal as well as external knowledge within an organization. Employees' participation in decision making process can also help an organization to improve its performance in terms of meeting the goals in an efficient way. Transformational leaders who consider their employees as intellectual capital are also an important ingredient of organizational success.

This study can also serve as an assessment tool to evaluate status of implementation of KM practices, hence spotting areas which need to be improved. Academic world can also use this study for better understanding of KM practices and to build models for the expansion of this domain.

\section{Limitations and future directions}

This study is aimed to study the impact of KM practices on organizational performance. Being students, we didn't have much access to very large local or multi-national organizations. Furthermore, we didn't have enough time to study the moderating role of any other factor between KM practices and organizational performance.

This study will help organizations as well as academic world to better understand and expand their knowledge about KM practices and their effect on organizational performance. Inclusion of a moderating variable like organizational culture or organizational change will expand the horizon of the study and will give the border picture of $\mathrm{KM}$ practices and its impact on Organizational Performance.

\section{References}

Anantatmula, V. S., \& Han, B. M. (2007). Knowledge sharing in large IT organizations a case study. The journal of information and knowledge management systems , pp. 421-439.

Arnold, A. J., Arad, S., Rhoades, J. A., \& Drasgow, F. (2000). The empowering leadership questionnaire:the construction and validation of a new scale for measuring leader behaviors. Journal of Organizational Behavior , 249-269. 
Arnold, K. A., \& Loughlin, C. (2010). Individually considerate transformational leadership behaviour and self sacrifice. Leadership \& Organization Development Journal , 670-686.

Bano, S., Rehman, K. U., \& Khan, M. A. (2010). Study of factors that impact knowledge management fit in corporate sector of pakistan. Far East Journal of Psychology and Business , 15-31.

Beugre, C. D., Acar, W., \& Braun, W. (2006). Transformational leadership in organizations:an environment-induced model. International Journal of Manpower, 52-62.

Birasnav, M., Rangnekar, S., \& Dalpati, A. (2011). Transformational leadership and human capital benefits: the role of knowledge management. Leadership \& Organizational Development Journal , 106126.

Bordum, A. (2010). The strategic balance in a change management perspective. Society and Business Review, 245-258.

Bryant, S. E. (2003). The Role of Transformational and Transactional Leadership in Creating, Sharing and Exploiting Organizational Knowledge. Journal of leadership and organzational studies , 32-44.

Carmeli, A., Sheaffer, Z., \& Halevi, M. Y. (2009). Does participatory decision-making in top management teams enhance decision effectiveness and firm performance? Personnel Review , 696-714.

Castiglione, J. (2006). Organizational learning and transformational leadership in the library environment. Library Management, 289-299.

Cheung, M. F., \& Wong, C. S. (2011). Transformational leadership,leader support, and employment creativity. Leadership \& Organization Development Journal , 656-672.

Crossman, J. (2010). Conceptualising spiritual leadership in secular organizational contexts and its relation to transformational, servant and environmental leadership. Leadership \& Organization Development Journal, 596-608.

de Jong, J. P., \& Den Hartog, D. N. (2007). How leaders influence employees' innovative behaviour. European Journal of Innovation , 41-64.

Elele, J., \& Fields, D. (2010). Participative decision making and organizational commitment Comparing Nigerian and American employees. Cross Cultural Management: An International Journal, 368-392.

Fronda, Y., \& Moriceau, J.-L. (2007). I am not your hero. Journal of Organizational Change Management, pp. 589-609.

Frucot, V., \& White, S. (2006). Managerial levels and the effects of budgetary participation on managers. Managerial Auditing Journal , 191-206.

Gao, F., Li, M., \& Clarke, S. (2008). Knowledge, management, and knowledge management in business operations. Journal of Knowledge Management, 3-17.

Gill, A. S., Flaschner, A. B., \& Shachar, M. (2006). Mitigating stress and burnout by implementing transformational leadreship. Internation Journal of Contemporary Hospitality Management , 469-481.

Harbi, S. E., Anderson, A. R., \& Amamou, M. (2011). Knowledge sharing processes in Tunisian small ICT firms. Library Review, 24-36.
Hautala, T. M. (2006). The relationship between personality and transformational leadership. Journal of Management Development, 777 794.

Jarboe, K. P., \& Alliance, A. (2011). Knowledge Management as an Economic Development Strategy . Washington, DC : Economic Development Administration, U.S. Department of Commerce .

Ladd, B. S., Travaglione, A., \& Marshall, V. (2006). Causal inferences between participation in decision making, task attributes, work effort, rewards, job satisfaction and commitment. Leadership \& Organization, 399-414.

Lin, H. F. (2007). Knowledge sharing and firm innovation capability: an empirical study. International Journal of Manpower, 315-332.

Liu, K. L., Chang, C. C., \& Hu, I. L. (2010). Exploring the effects of task characteristics on knowledge sharing in libraries. Library Review , 455468 .

McGuire, D., N. Garavan, T., K. Saha, S., \& O’Donnell, D. (2006). The impact of individual values on human resource decision-making by line managers. International Journal of Manpower, pp. 251-273.

Nguyen, N. H., \& Mohamed, S. (2011). Leadership behaviors, organizational culture and knoeledgge management practices: An empirical investigation. Journal of Management Development, 206-221.

O’Neill, B. S., \& Adya, M. (2007). Knowledge sharing and the psychological contract. Journal of Managerial Psychology, pp. 411-436.

Parnell, J. A., \& Crandall, W. R. (2001). Rethinking participative decision making: A refinement of the prospenity for participative decision making scale. Personnel Review, 523-535.

Parolini, J., Patterson, K., \& Winston, B. (2009). Distinguishing between transformational and servant leadership. Leadership \& Organization Development Journal , 274-291.

Russ, T. L. (2011). Theory $\mathrm{X} / \mathrm{Y}$ assumptions as predictors of managers' propensity for participative decision making. Management Decision , 823836.

Schneider, S. K., \& George, W. M. (2011). Servant leadership versus transformational leadership in voluntary service organizations. Leadership \& Organization Development Journal , 60-77. Selart, M. (2005). Understanding the role of locus of control in consultative decisionmaking: a case study. Management Decision, 397-412.

Singh, N., \& Krishnan, V. R. (2008). Self-sacrifice and transformational leadership: mediating role of altruism. Leadership \& organization Development Journal , 261-274.

Sukirno, D. S., \& Siengthai, S. (2011). Does participative decision making affect lecturer performance in higher education? International Journal of Educational Management, 494-508. Watanabe, R. M., \& Senoo, D. (2010). Shaping knowledge management: organizational and national culture. Journal of Knowledge Management, 214-227.

Xue, Y., Bradley, J., \& Liang, H. (2011). Team climate, empowering leadership, and knowledge sharing. Journal of Knowledge Management, 299-312. 